\title{
perifèria
}

Número 5, Diciembre 2006

www.periferia. name

\section{Em breve um país dividido? O Brasil do século XXI e as novas políticas públicas com base na "raça"}

\author{
Yvonne Maggie - Instituto de Filosofía y Ciencias Sociales de la UFRJ ${ }^{1}$
}

\section{Resumen}

Históricamente Brasil se ha caracterizado por tener una legislación a-racial al utilizar un sistema clasificatorio con varias posibilidades de categorías, evitando así la polarización "blanco" versus "negro".

En el año 2001 la situación cambió debido a la postura del Gobierno brasileño referente a la cuestión racial al proponer "acciones afirmativas" a favor de la "población afro-descendiente". En 2005 se aprobaron dos proyectos de ley en el Congreso Nacional que establecen cuotas para "negros" en las universidades y en todas las esferas de la vida social, y por tanto, la obligación de identificación racial en los documentos oficiales. De esta forma pasan a existir legalmente dos figuras de derecho: negros y blancos.

La respuesta ha sido una Carta Pública al Congreso Nacional escrita por un grupo de intelectuales, artistas y líderes sociales, donde se reafirman los principios universalistas de nuestra sociedad y cultura. La reacción de los defensores de las cuotas no se hizo esperar, creándose así dos posiciones enfrentadas.

A lo largo de dos años hicimos observación participante en escuelas de Río de Janeiro, participando de todas sus actividades e hicimos entrevistas e historias de vida. Fue una minuciosa etnografía (cualitativa) a la que se añadió una investigación más cuantitativa mediante preguntas.

\begin{abstract}
Historically, Brazil has defended a legal system without the use of "race" categories and of course the opposition "White" against "Black". In 2001 the Brazilian Government approved positive measures in order to beneficiate "population with afro-origins". Again, in 2005, it is imposed a quota system for black people in the universities and in the rest of social life, giving a legal existence the figures of Blacks and Whites.

Against this trend, a group of artists, intellectuals and social leaders has reacted with a Public Letter to the National Congress claiming for the maintenance of the principles of universality. This position has created an argument between defenders of both positions which is the object of this qualitative and quantitative research.
\end{abstract}

\footnotetext{
${ }^{1}$ Conferencia inaugural del curso invitada por el Departament d'Antropologia social i cultural de la UAB. 0ctubre 2006. Enviar correspondencia a: yvonnemaggie@terra.com.br
} 


\section{perifèria}

Número 5, Diciembre 2006

www.periferia. name

\section{I ntrodução}

Nossa Constituição reconhece e condena o racismo, punindo-o como crime inafiançável. Nesse sentido mantém a longa tradição formal republicana brasileira do a-racismo e do anti-racismo. O Brasil se caracteriza por ter uma legislação aracial desde que aboliu a escravidão. Essa característica de nosso sistema jurídico produziu uma sociedade, ou foi produzida por uma sociedade, que não se caracterizou por dar ênfase a marcadores raciais. O resultado foi a constituição de um sistema classificatório que utiliza muitas categorias num gradiente de claro a escura e o uso muito restrito das oposições preto e branco ou negro e branco.

Os brasileiros até então se classificavam segundo cores e a partir de três domínios.

O primeiro deles pode ser chamado assim de domínio da cultura, aí usamos as categorias em oposição negro e branco e é claro o índio, categorias que denotam a origem do indivíduo, o seu pertencimento étnico, por assim dizer. O segundo refere-se ao domínio propriamente social e aí, até a pouco, usávamos a tríade branco e preto e pardo que denota o lugar social do indivíduo. Finalmente, um terceiro domínio é aquele do dia a dia, do cotidiano e usa um gradiente que vai do claro ao escuro passando por todos os matizes e que está ao mesmo tempo no reino da cultura, posto que adjetiva o indivíduo tornando-o mais ou menos escuro e no reino do social porque nos extremos do gradiente há sempre a luz e a ausência dela, o branco e o preto.

Tudo isso parece estar mudado radicalmente.

O Brasil deve se pensar agora a partir das categorias "negro" e "branco" construídas para desvendar a nossa estrutura social e não a partir de seu gradiente de cor que aproxima os pólos negro e branco. Esta nova versão da nossa cultura põe por terra o ideário modernista criado nos anos 1920 e que dominou e ainda domina as diversas correntes estéticas do nosso país influenciando a vida e o cotidiano dos brasileiros de todas as cores. 


\section{perifèria}

Número 5, Diciembre 2006

www. periferia. name

De fato tudo parece ter começado muito antes ${ }^{2}$, mas só nos apercebemos da mudança no alvorecer do século XXI, quando da preparação do Brasil para a III Conferência Mundial das Nações Unidas de Combate ao Racismo, Discriminação Racial, Xenofobia e Intolerância Correlata, sediada na África do Sul, em $2001^{3}$. Foi nesta Conferência que a postura do governo brasileiro perante a questão racial mudou radicalmente. A delegação oficial brasileira propôs "ações afirmativas" em favor da "população afro-descendente", entre elas o reconhecimento oficial da legitimidade de reparações para com a escravidão e cotas para negros nas universidades públicas.

Ao longo desses últimos cinco anos, 26 universidades públicas introduziram diferentes formas de inclusão em seus vestibulares, a maioria esmagadora delas com reserva de vagas para estudantes negros. O Ministério da Educação fez programas especiais para negros e o Ministério da Saúde iniciou políticas voltadas exclusivamente para negros. O governo criou também em 2003, logo depois da posse de Luiz Inácio Lula da Silva, a Secretaria Especial de Promoção da Igualdade Racial e para ela nomeou representantes dos movimentos negros. Dois projetos de lei tramitavam no Congresso Nacional, o projeto que institui cotas raciais nas universidades públicas (PL73/1999), que foi apoiado pelo pelo Ministério da Educação em 2005 e o Estatuto da Igualdade Racial (PL 3.198/2000). Ambos os projetos estabelecem cotas para negros em todas as universidades federais e, no caso do Estatuto da I gualdade Racial, cotas para negros em todas as esferas da vida social e obrigatoriedade de identificação racial nos documentos oficiais.

O Brasil viu-se, assim, no início do novo século com uma proposta de modificação da nação. Nossa legislação a-racial e todo o arcabouço jurídico brasileiro até a constituição de 1988 pregavam o combate ao racismo como crime inafiançável e tratava os cidadãos como iguais. Agora estes projetos de lei propõem tratar "desigualmente os desiguais", construindo assim um país legalmente dividido em duas figuras de direito - brancos e negros.

\footnotetext{
${ }^{2}$ Ver sobre a história da construção desse discurso de verdade, Monteiro (2003).

${ }^{3}$ Sobre um histórico desse debate ver Fry e Maggie (2005).
} 


\section{perifèria}

Número 5, Diciembre 2006

www.periferia. name

O rastilho de pólvora pegou fogo e a sociedade brasileira, compadecida com o drama dos pobres e do racismo, tudo assistiu quase que silenciosa a estas novas propostas que pululavam. Nossa sociedade passou a ser descrita através de uma lógica ou modelo estatístico. Essa lógica implica em descrever a vida social como se fosse uma tabela estatística. Assim, aparece um discurso que fala em "fosso" entre brancos e negros. Esse novo discurso de verdade sobre o Brasil estava se tornando hegemônico quando um grupo de intelectuais, artistas e lideranças do movimento negro decidiram escrever uma Carta Pública ao Congresso Nacional e nela reafirmaram os princípios universalistas da nossa sociedade e cultura. A Carta Pública gerou uma reação imediata dos proponentes das cotas, que fizeram o seu Manifesto a favor das cotas e levaram-no também aos presidentes do Senado e da Câmara. Estes dois documentos assim confrontados espelham duas posições que estão agora no debate público exigindo do governo e dos representantes que se posicionem e reflitam sobre as conseqüências da adoção de um ou outro dos caminhos propostos.

No alvorecer do século XXI ocorreu, então, uma espécie de terremoto na maneira pela qual o Brasil pensa o Brasil. As recentes proposta de políticas públicas baseadas na "raça", transformam radicalmente a nossa concepção de nação misturada da "fábula das três raças" que foi questionada e parece estar cedendo lugar para uma noção de nação dividida entre negros e brancos.

Pela primeira vez na nossa história desde os anos 1920, a elite brasileira parece ter colocado por terra as bases do pensamento que permitiu a criação de nossa cultura mais radicalmente nacional e cosmopolita. O ideário da brasilidade modernista de Mário e Oswald de Andrade, de Paulo Prado e Sérgio Buarque de Holanda, de Gilberto Freire e Di Cavalcanti, de Tarsila do Amaral e Anita Malfati está sob suspeição. Todo o esforço empreendido nos anos 1930 para positivar a mestiçagem parece estar sendo colocado por terra.

\section{Uma breve digressão sobre o ideário modernista}

Farei aqui uma breve digressão sobre a história cultural de como chegamos a ter esse sistema tomando a nossa cultura mais erudita. 


\section{perifèria}

Número 5, Diciembre 2006

www. periferia. name

Em 1928 Mário de Andrade publicava o clássico Macunaíma um herói sem nenhum caráter dedicado a Paulo Prado, que publicaria no final do mesmo ano o seu Retrato do Brasil. O romance é uma história baseada em lendas e mitos brasileiros ${ }^{4}$. 0 personagem central, Macunaíma, foi construído a partir da descrição feita pelo naturalista alemão Theodor Koch-Grünberg em Vom Roroima zum Orinoco (Do Roraima ao Orenoco) publicada, em cinco volumes, entre 1916 e 1924.

Mario não estava só nesta empreitada que foi a de sua geração. Seu argumento, no entanto, não surgia do nada. É preciso lembrar que se ancorava em idéias enraizadas na nossa cultura já no século XIX basta pensar na tese de Carl F. von Martius para o Instituto Histórico e Geográfico Brasileiro em $1836^{5}$. Carl F. von Martius (1864), vencedor do concurso do IHGB com a monografia Como se deve escrever a história do Brasil, marcou o futuro de nossa historiografia ao descrever nossa história a partir da mescla de brancos, negros e índios na "raça brasileira" usando a metáfora do encontro entre três rios. O argumento da "raça" era tão forte que Mario numa primeira versão de Macunaíma teria optado pelo epíteto de "herói de nossa raça". Só mais tarde é que mudou para "herói de nossa gente".

Mario e a geração modernista pensavam que a história era ancorada no mais profundo inconsciente da nossa sociedade, a ponto de Oswald chamar o romance de a Odisséia brasileira. Será que pensavam mal? Teria sido toda essa invenção de um país misturado, mestiço e onde o mito de igualdade entre as "raças" estava no cerne da utopia, uma ficção de uma elite que não conhecia e nem via o que estava à sua volta? Seria esta uma invenção ou mito, no sentido de farsa ou mentira, que ganhou o mundo, transformando o nosso destino de uma sociedade inviável, porque mestiça, em desiderato e fonte de todo o espanto?

\footnotetext{
${ }^{4}$ Gilda de Mello e Souza (2003 [1979]) em o Tupi e o Alaúde faz uma das mais belas leituras do romance e vê a sua estrutura também toda feita da mistura, do bricolage. Lendo esse livro recentemente reeditado fiquei mais ainda impressionada porque a autora de forma clara e precisa mostra como o livro é uma meditação "extremamente complexa sobre o Brasil". A leitura que a autora propôs "é menos a de uma interpretação triunfal e retoma a indicação pessimista de Mario...". Certamente a afirmação que vejo no romance não é de modo algum incompatível com essa visão ambivalente. Afinal, foi na nossa cultura mestiça, misturada e ambígua que, como mostrou Gilda de Mello e Souza, Mario foi beber mesmo estando também mergulhado na cultura mais cosmopolita e universal.

5 Monoel Luiz Salgado Guimarães tem uma importante contribuição para a discussão desse livro fundador da historiografia brasileira. Ver Guimarães ( 1987).
} 


\section{perifèria}

Número 5, Diciembre 2006

www. periferia. name

Mas terá sido esta uma quimera de um grupo da elite que estava ausente da nossa realidade? Gilberto Freire ([1933] 1995) foi um dos que estavam na trilha modernista e Casa Grande e Senzala teve a primeira edição revista por Mário de Andrade $^{6}$. Era preciso transformar o país do pesadelo do Conde Gobineau ${ }^{7}$, que só via um fim trágico para tanta mistura, em uma utopia que nos colocaria em pé de igualdade com a Europa de Descartes ${ }^{8}$. Falo aqui do "pesadelo de Gobineau", porque ele é quase um ícone de uma geração de adeptos do darwinismo racial ${ }^{9}$ que jogou todas as suas fichas na idéia de que um país de "raças" mistas era inviável. Esse não era apenas o seu pesadelo mas o grande fantasma que atormentou uma geração de pensadores do século XIX e que volta aqui e ali a assombrar ainda no século XX. Parece que o pesadelo renasce nessa grande mudança do século que vivemos no século XXI. Afinal, a versão de um país dividido em brancos e negros é uma versão contemporânea da idéia de que a mistura é ruim e nos torna inviáveis.

Assim, uma geração de escritores e artistas pintou o Brasil da Mulata de Di Cavalcanti $^{10}$, do Abapurú e da Negra de Tarsila do Amaral ${ }^{11}$. E algumas gerações depois deles continuaram pensando e inventando um país que não teme esta mistura e faz dela delícia e desgraça de ser o que somos. Não vou nomear todos,

\footnotetext{
${ }^{6} \mathrm{O}$ estudo mais completo que rediscute Casa Grande e Senzala apresentando uma análise complexa dessa obra é o de Araújo (1994). É preciso também discutir a expressão democracia racial que foi muitas vezes atribuída a Gilberto Freire e segundo Guimarães (2002) foi cunhada mais tarde, por Roger Bastide e não em Casa Grande e Senzala.

7 O Conde Arthur de Gobineau foi embaixador Francês no Brasil e escreveu em meados do século XIX o livro Ensaio sobre a desigualdade das raças (1853). Nos anos em que permaneceu no Brasil como chefe da delegação diplomática, segundo relato minucioso de Lilia Schwarcz "parecia respeitar apenas o imperador do Brasil... todos os demais na opinião desse embaixador francês, 'pareciam-se como macacos'" Schwarcz (1998 p. 372). O conde Gobineau tinha uma visão pessimista sobre a miscigenação que era para ele sinal de degeneração que fazia com que não houvesse futuro para nosso país. Lilia Schwarcz (1993) discutiu a obra de Gobineau e o debate que se travava entre pensadores daquela época em seu livro O espetáculo das raças. Segundo Lilia Schwarcz as idéias de Gobineau repercutiram mais no Brasil do que no exterior.

8 É preciso também ler Schwarcz (1999) sobre a importância de Casa Grande e Senzala para a interpretação da sociedade brasileira. Diz Schwarcz: “ O 'cadinho de raças' aparecia como uma versão otimista, mais evidente aqui do que em qualquer outro lugar: 'Todo o brasileiro, mesmo o alvo, de cabelo louro, traz na alma quando não na alma, e no corpo, a sombra, ou pelo menos a pinta, do indígena e/ ou do negro', afirmava Freire fazendo da mestiçagem uma questão ao mesmo tempo nacional e distintiva." Schwarcz (1999 p.276).

${ }^{9}$ Para uma análise do pensamento racial no século XIX ver Schwarcz (1993).

${ }^{10}$ Ver a mulata de Di, Cavalcanti de 1928 no site Di Cavalcanti www.dicavalcanti.com.br/que apresenta toda a obra do pintor.

${ }^{11}$ O Abapurú de Tarsila de 1928 e a Negra de 1923 no Site /www.tarsiladoamaral.com.br/
} 


\section{perifèria}

Número 5, Diciembre 2006

www. periferia. name

mas não se pode esquecer dos Concretos, e, sobretudo, de Augusto de Campos e seu poema Luxo. E o que dizer então do movimento tropicalista e daqueles jovens dos anos 1960 que até hoje compõem canções que falam do nosso paradoxo de ser Haiti e não ser o Haiti ${ }^{12}$. Também não se deve esquecer do clássico filme de Joaquim Pedro de Andrade que em 1969 faz uma releitura de Macunaíma transformando o livro em obra cinematográfica que revela a contemporaneidade daquele livro de 1928. E o que dizer então dos trabalhos de Luiz Alphonsus O Conceitual Caboclo ${ }^{13}$ e Índia e Mato - paródia e metáfora da Negra de Tarsila - se não fosse essa interpretação do Brasil inaugurada por Mário de Andrade e os modernistas na década de 1920.

Terá sido todo esse esforço e muitos livros inesquecíveis na nossa memória escritos em vão? Teriam sido seus autores apenas copiadores de uma mensagem que acabou como ideologia, transfigurando-se em refúgio de uma elite racista, como dizem muitos hoje?

Para responder a esta pergunta e a tantas outras que nos afligem hoje fomos mergulhar no universo escolar e ver o que se passava nessas salas de aula e pátios escolares onde estudam meninos de meninas brasileiras, o que aprendem eles sobre a nossa história e como enfrentam os desafios que estão diante deles.

Nossa hipótese é que estas políticas ora propostas irão afetar não a elite branca como dizem, mas aqueles meninos e meninas que estão nessas escolas e querem ter uma vida melhor do que a de seus pais como disseram ao responder a um questionário que aplicamos no final de 2005 aos estudantes dessas escolas pesquisadas.

\footnotetext{
12 Caetano Veloso e as canções Haiti e Americanos.

${ }^{13} \mathrm{O}$ artista plástico Luiz Alphonsus, da geração Conceitual, só para cita um deles fez dois trabalhos que remetem a esta influência modernista. O Conceitual Caboclo e índia e Mato fazem parte da Coleção Gilberto Chateaubriand.
} 


\section{perifèria}

Número 5, Diciembre 2006

www.periferia. name

\section{Preconceito e discriminação}

Ao longo dos últimos dois anos fizemos observação participante nessas escolas, descrevendo-as em seus rituais, cerimônias e coletando entrevistas e histórias de vida. Pesquisadores, estudantes de graduação, mestrado e doutorado, principalmente meninas, mas também alguns meninos, de cores variadas, todos muito jovens e muitos deles recém saídos das escolas pesquisadas orientados pela coordenadora, fizeram assim estudos de caso intensivo nas escolas pesquisadas. Os jovens pesquisadores fizeram minuciosas etnografias indo várias vezes por semana nas suas escolas, conversando com professores, estudantes e funcionários, participando de todos os rituais, como os conselhos de classe, as festas e comemorações, além de freqüentarem aulas rotineiras. Além dessa observação na escola, visitaram alunos e professores em seus locais de moradia, e em alguns casos as entrevistas foram feitas na casa do aluno ou do professor. Mas o trabalho mais intenso foi realizado na escola. Os pesquisadores foram treinados para olhar as escolas como se estivessem em uma distante ilha do pacífico ocidental mesmo sabendo que a ilha estava imersa em uma sociedade urbana e complexa. Nas reuniões semanais da pesquisa os pesquisadores relatavam seus achados e perplexidades e não houve nenhum que não tivesse dito que estas escolas eram muito mais ricas do que se diz em geral sobre o nosso sistema educacional. Lá estavam as escolas bem com salas de aula, muitas com laboratórios de informática, bibliotecas pequenas mas razoáveis e diretores empenhados em suas tarefas. 0 que mais impressionou a todos foi, no entanto, a chamada pedagogia da repetência que transforma todo o esforço empreendido pelas famílias e pelos alunos e mesmo pelos mestres em um eterno repetir a série cursada. Poucos se formam no ensino médio e em muitas dessas escolas a reprovação no primeiro ano chega a $40 \%$ dos alunos.

Em novembro de 2005, como um desdobramento da pesquisa qualitativa, fizemos um survey nas 21 escolas cariocas que eram objeto de estudos de caso intensivo sendo 19 delas da rede estadual, 1 da rede federal e 1 da rede particular. Entre as 21 escolas da rede estadual, 19 tinham tido baixo desempenho na avaliação feita anualmente pela Secretaria de Educação, o Programa Nova Escola e estavam sendo 


\section{perifèria}

Número 5, Diciembre 2006

www.periferia. name

objeto de uma política especialmente desenhada para melhorar o seu desempenho. As duas outras eram escolas consideradas boas nesta avaliação. A escola da rede particular e da rede federal são escolas consideradas de excelência. As 19 escolas da rede estadual estão localizadas em bairros pobres do estado ou em bairros próximos a comunidades pobres. As duas escolas de excelência localizam-se em bairros ricos da cidade. Fizemos perguntas a 391 estudantes destas escolas em uma amostra feita a partir do universo de estudantes que freqüentam estas 21 escolas. É assim uma amostra das opiniões dos estudantes dessas 21 escolas. Os resultados têm uma margem de erro de $5 \%$ para mais ou para menos ${ }^{14}$. Essa pesquisa mais quantitativa, sabemos, tem muitos limites e deve ser tomada apenas como uma precária bússola nesse mar agitado da realidade social, pois ela não pode ser tomada como representativa de todas as escolas cariocas e muito menos brasileiras.

O resultado da pesquisa qualitativa mostrava uma realidade em que o racismo e a discriminação, embora presentes no cotidiano dessas escolas, não eram temas de conversas e não pareciam interessar estes jovens. Vários assuntos animavam as conversas, mas o que mais era discutido era a qualidade da escola, a qualidade dos professores e a repetência. Alunos e professores discutiam a qualidade da escola e se colocavam do mesmo lado diante desta realidade. Por que os alunos eram tão reprovados? Alunos e professores colocavam a causa nos próprios alunos e na realidade brasileira, pobreza, tráfico de drogas, famílias desestruturadas. Os professores culpavam a aprovação automática que segundo eles teria produzido essa "débâcle" na educação do estado. Os professores, diferentemente dos alunos, diziam que eles não "queriam nada", que "não tinham jeito" e outras frases menos delicadas.

Decidimos então ir direto ao assunto e perguntar sobre preconceito e discriminação na escola.

\footnotetext{
${ }^{14}$ Ver sobre a pesquisa o relatório de 2006 no site www.observa.ifcs.ufri.br
} 


\section{perifèria}

Número 5, Diciembre 2006

www.periferia. name

Fizemos a pergunta sobre "cor/ raça" do censo demográfico ${ }^{15}$ aos entrevistados e tivemos a seguinte distribuição: $35,5 \%$ se autodeclararam brancos, $39,5 \%$ se autodeclararam pardos e $25 \%$ se autodeclararam pretos. Verificamos que estes dados revelam uma população estudantil mais escura que a população do estado do Rio de Janeiro que segundo o censo 2000 compõe-se de 53,9\% brancos, 33,7\% pardos, $10,9 \%$ pretos e menos de $1 \%$ amarelos e indígenas. Os resultados do Enem em 2001 mostram que os concluintes do ensino médio naquele ano de 2001 eram compostos por $58,5 \%$ de brancos, 36 , \% de mulatos e negros ${ }^{16}$ sendo $30,5 \%$ de pardos, $6,3 \%$ de negros.

A pesquisa revelou que há diferenças de percepção da discriminação e do preconceito por parte dos respondentes tomando-os separadamente segundo a "cor/raça", mas também que há percepções semelhantes entre os respondentes.

Apenas $16,4 \%$ dos autodeclarados brancos, $20,9 \%$ dos autodeclarados pretos e $15,4 \%$ dos autodeclarados pardos disseram ter sofrido algum tipo de preconceito/discriminação na escola, o que é um indicador de que não se sentem muito discriminados.

Quando perguntamos aos que afirmaram ter sofrido discriminação quais os motivos da discriminação que sofreram, alegaram os seguintes motivos em ordem decrescente: por causa da "cor/ raça"; por ser pobre; por ser mulher; por ser ou parecer homossexual; por ser gordo; por ser bom aluno e finalmente por ser mau aluno. Entre os $20 \%$ que disseram terem sido discriminados, $86,7 \%$ dos autodeclarados pretos; $8,3 \%$ dos autodeclarados brancos e 14, \% dos autodeclarados pardos afirmaram ter sofrido preconceito ou discriminação por causa de sua "cor/ raça". A maioria afirmou que tinham sido outros alunos a discriminá-los. $41 \%$ dos autodeclarados brancos disseram terem sido discriminados

\footnotetext{
${ }^{15}$ O censo demográfico realizados pelo Instituto Brasileiro de Geografia e Estatística IBGE utiliza há 100 anos um modelo padrão de pergunta em que se pede aos entrevistados que se autoclassifiquem diante das seguintes opções: branco, preto, pardo, amarelo e indígena. Decidimos manter a pergunta para permitir a comparabilidade.

${ }^{16} \mathrm{O}$ Enem utilizou as categorias negro e mulato em vez de pretos e pardos como é tradicional em pesquisas censitárias desde o final do século XIX.
} 


\section{perifèria}

Número 5, Diciembre 2006

www. periferia. name

por ser bom aluno, ao passo que $14 \%$ dos pardos afirmaram ter sofrido esse preconceito e nenhum autodeclarado preto disse o mesmo ${ }^{17}$.

Já quando perguntados se viram alguma situação de preconceito/discriminação na escola $40 \%$ dos estudantes disseram que presenciaram esse tipo de situação. Mas quando perguntamos sobre os motivos da discriminação que viram outros sofrerem aparece uma hierarquia diversa daquela que havia surgido quando da pergunta sobre se sofreram algum tipo de discriminação. Dos autodeclarados brancos $37 \%$ parecem ter presenciado mais discriminação por causa da "cor" ou "raça", e todos os estudantes, independentemente de sua "cor/raça", viram mais pessoas sendo discriminadas por ser ou parecer homossexual.

Também perguntamos se achavam que seus mestres tendiam a discriminar seus alunos pela cor ou posição social e as respostas foram também muito impactantes. Entre os que disseram que os professores tendiam a discriminar os alunos pobres, $13,7 \%$ eram autodeclarados brancos, $11,8 \%$ autodeclarados pretos e $11,1 \%$ autodeclarados pardos.

Mas dos que responderam que os professores tendiam a discriminar alunos negros, 9,8\% eram autodeclarados brancos, $14,5 \%$ eram autodeclarados pretos e $13,6 \%$ eram autodeclarados pardos o que indica que pretos e pardos se acham mais discriminados pelos seus mestres por causa da cor. Ou seja, a maioria dos entrevistados não pensa ou sente que os professores discriminam os alunos negros ou pobres.

$16,1 \%$ dos estudantes entrevistados responderam que achavam que os professores não acreditam na vontade de estudar de alunos negros. Dentre esses, $11,3 \%$ dos autodeclarados brancos, $22 \%$ dos autodeclarados pretos e $16,5 \%$ dos autodeclarados pardos disseram que sim. Essa resposta nos leva a pensar que os

\footnotetext{
17 Foi difícil estabelecer essa hierarquia porque apenas $20 \%$ dos entrevistados afirmaram que tinham sofrido preconceito o que dificulta qualquer análise mais acurada.
} 


\section{perifèria}

Número 5, Diciembre 2006

www. periferia. name

autodeclarados pretos sentem mais que seus professores não acreditam na vontade de estudar de alunos negros do que os autodeclarados pardos e brancos.

Mas essa resposta se comparada à outra dada para a pergunta sobre se os professores não acreditam na vontade de estudar de alunos pobres talvez indiquem que pobreza e cor estejam associadas, pois $12,6 \%$ dos autodeclarados brancos, $20,9 \%$ dos autodeclarados pretos e $16,5 \%$ autodeclarados dos pardos acham que os professores não acreditam na vontade de estudar dos alunos pobres. Ou seja, pretos e pardos são os que mais sentem que os professores não acreditam na vontade de aprender dos alunos pobres.

Finalmente perguntamos se na escolha de seus namorados a cor ou o nível social do parceiro era levado em consideração. Os números mostram que, na hora da escolha, a cor do parceiro é indiferente para a maioria dos entrevistados. Entre os autodeclarados brancos, $6,6 \%$, disseram que preferiam parceiros mais escuros enquanto $4,9 \%$ disseram que preferiam mais claros, $20,5 \%$ da mesma cor e $68 \%$ disseram que era indiferente. Entre os autodeclarados pretos, 2,3\% disseram que preferiam parceiros mais escuros, $9,3 \%$ preferiam parceiros mais claros, 5,8\% preferiam parceiros da mesma cor e $82,6 \%$ achavam indiferente a cor na sua escolha de namorados. Entre os autodeclarados pardos, 5,9\% disseram que preferiam parceiros mais escuros, $8,9 \%$ preferiam mais claros, $15,6 \%$ preferiam parceiros da mesma cor e $69,6 \%$ disseram ser indiferente. Ou seja, parece que para os entrevistados a cor do parceiro é indiferente na hora da escolha de seus namorados, o que sugere que os estudantes são, até agora, bastante color blind nas suas escolhas amorosas. ${ }^{18}$

$\mathrm{Na}$ escolha dos namorados eles são menos indiferentes quando se trata do nível social dos seus parceiros. Entre os autodeclarados brancos, 6,6\%, afirmaram que preferiam mais ricos, $0,8 \%$ mais pobres e $55,4 \%$ disseram que eram indiferentes. Dos autodeclarados pretos, 9,3\%, disseram que preferiam parceiros mais ricos, $1,2 \%$ preferiam mais pobres, $37,2 \%$ mesma faixa de renda e para $52,3 \%$ era indiferente. Já dos autodeclarados pardos, 5,2\% preferiam mais ricos, $0,7 \%$

\footnotetext{
${ }^{18}$ Não foi possível cruzar as preferência por sexo, porque os números são insuficientes.
} 


\section{perifèria}

Número 5, Diciembre 2006

www.periferia. name

preferiam parceiros mais pobres, 34,1 da mesma faixa de renda e para $60 \%$ o nível social do parceiro era indiferente. Os nossos entrevistados, então, parecem ser muito democráticos nas suas escolhas amorosas e não levam em consideração o nível social e a cor do parceiro na hora da escolha. No entanto, comparando o critério social e o racial, os estudantes parecem ser mais indiferentes quando se trata da cor/ "raça" dos parceiros e menos indiferentes quando se trata da posição social do parceiro ${ }^{19}$.

Os números, é claro, não nos autorizam a dizer que em todas as escolas brasileiras ou mesmo cariocas os estudantes pensam desta forma. Sabemos dos limites de qualquer pesquisa qualitativa. No entanto, eles confirmam o que vimos no trabalho de campo e os relatos de muitos estudantes sobre suas experiências na escola.

Preconceito e discriminação não são até agora tema central na vida dos estudantes dessas escolas. Mas podemos ver pelos números, algumas tendências. Parece que os estudantes autodeclarados pretos sentem mais a discriminação e o preconceito que os autodeclarados brancos e os pardos.

No entanto, parece que essas situações de discriminação ou preconceito vividas se dão muito mais entre colegas. Na observação de campo o que apareceu foram xingamentos, gozações, brincadeiras entre colegas que foram vividas como preconceito ou discriminação.

Podemos perceber uma tendência geral a uma espécie de hierarquia de xingamentos na escola. Assim, a referência pejorativa à homossexualidade parece ser o mais freqüente sendo seguido por xingamentos referentes à "raça" (aí precisamos ver também se há entre os que dizem ter visto situação de preconceito ou discriminação quanto à cor, xingamentos e referências desairosas à cor branca o que os números não dizem), em terceiro lugar viria a pobreza, em quarto parece

\footnotetext{
${ }^{19}$ Para uma análise mais fina sobre as escolhas amorosas e a cor dos parceiros ver Moutinho (2005)
} 


\section{perifèria}

Número 5, Diciembre 2006

www.periferia. name

haver uma tendência a xingamentos quanto à gordura do colega e por fim ainda ser bom ou mau aluno ${ }^{20}$.

Por fim, os dados apresentados mostram que autodeclarados brancos e autodeclarados pretos se sentem mais discriminados por cor que os autodeclarados pardos.

Mas os números dizem algo mais. Os autodeclarados pretos parecem levar menos em consideração a cor dos parceiros que os autodeclarados brancos e pardos na escolha de seus parceiros. Dos autodeclarados pretos $82 \%$ disseram que era indiferente a cor dos parceiros na hora da escolha enquanto para os autodeclarados brancos e pardos apenas $69 \%$ disseram isso.

Os dados apresentados aqui talvez nos autorizem a dizer que os estudantes escolhem como estratégia desprezar marcadores "raciais" nas suas escolhas amorosas, indicando assim que suas preferências são mais baseadas nas características pessoais dos parceiros do que nas suas características grupais, por assim dizer.

Aliás, não precisávamos de muitos números para comprovar essas indicações do survey. Bastava andar pelo pátio cheio de meninos e meninas com uniformes sempre arrumados e sempre com algum toque que individualiza como uma saia enrolada na cintura para ser encurtada, uma blusa cortada mais em cima da cintura para mostrar a barriga e muitas bijuterias. Os cabelos minuciosamente penteados com muitos estilos dos mais tradicionais aos mais ousados. As meninas sempre com pregadores coloridos para enfeitar os cabelos lisos e outras com tranças ao estilo afro e, muitos meninos, com os cabelos cheios de gel em um estilo semelhante aos punks. Piercings em muitas partes do corpo e algumas tatuagens ousadas. Tudo isso dando um colorido juvenil e cosmopolita a estas escolas onde convivem jovens de várias faixas etárias, pois sendo a repetência alta há uma enorme distorção entre as idades e as série cursadas.

\footnotetext{
${ }^{20}$ Este resultado parece ser consistente com as recentes pesquisas sobre o tema, conforme pode ser visto em CARRARA, Sérgio, RAMOS, Silvia (2005).
} 


\section{perifèria}

Número 5, Diciembre 2006

www. periferia. name

Nesse ambiente e ao longo desses dois anos de pesquisa vimos alguma brigas entre colegas por causa de xingamentos ofensivos à cor. "Negro", "negrinha", "macaco", "bombril", "favelada" e muitas outras palavras são usadas como xingamento. No entanto, o que mais apareceu foram sempre acusações e referências à virilidade de meninos. Alguns sofrem muito sendo chamados de "bichas", "emos", “maricas", "mulherzinha"e tantos outros nomes. Há mesmo agressões físicas nos pátios e coros em que muitos, levantando a voz, chamam um colega de "bicha". Esse comportamento parece ser em geral jocoso e a forma de reagir do ofendido pode ser crucial para que a brincadeira se torne uma agressão física.

Os xingamentos e ofensas em relação à cor/ "raça" estão sempre associados ao rompimento da etiqueta racial brasileira que escolheu falar naquilo que aproxima e não no que separa e opõe. Falamos no Brasil ou usávamos no Brasil até a bem pouco tempo três domínios de classificação racial ${ }^{21}$. O primeiro deles pode ser chamado assim de domínio da cultura, aí usamos as categorias em oposição negro e branco que denotam a origem do indivíduo, o seu pertencimento étnico, por assim dizer. O segundo refere-se ao domínio propriamente social e aí, até a pouco, usávamos a tríade branco e preto e pardo que denota o lugar social do indivíduo. Finalmente, um terceiro domínio é aquele do dia a dia, do cotidiano e usa um gradiente que vai do claro ao escuro passando por todos os matizes e que está ao mesmo tempo no reino da cultura, posto que adjetiva o indivíduo tornando-o mais ou menos escuro e no reino do social porque nos extremos do gradiente há sempre a luz e a ausência dela, o branco e o preto.

Convivemos nas escolas com aquelas três formas de se referir às diferenças de cor entre alunos e entre professores. Nosso sistema de nominação de cores até hoje no Brasil escolheu reforçar aquilo que aproxima os pólos opostos. Assim, inventou-se um sistema que individualiza, e pelo gradiente transforma cada indivíduo em um

\footnotetext{
${ }^{21}$ Sobre esse tema escrevi em 1994 um primeiro artigo apresentando o resultado da pesquisa de campo sobre as comemorações do centenário da abolição em 1988. Este artigo foi repensado por mim em outro escrito em 2005 em que retomo algumas das conclusões de 1994.
} 


\section{perifèria}

Número 5, Diciembre 2006

www. periferia. name

ser de cor única e própria. Peter Fry (2005) já havia descrito esse nosso sistema de individuação seguindo Olivia Gomes da Cunha que descobriu "que os indivíduos são identificados e classificados segundo a combinação singular de características "raciais" traída pelas medidas de seus corpos" apud Fry (2005 p. 215).

Só raramente se usa as categorias em oposição que, ao contrário, denota o pertencimento da pessoa a um grupo. Há, ou havia, sempre o cuidado extremo de nunca usar essas categorias para se referir a alguém próximo. As categorias são sempre usadas quando se fala em um terceiro distante, sobretudo a que estão em oposição. Para os próximos usa-se o gradiente de cor, individualizando, aproximando e amenizando as oposições ${ }^{22}$.

Mas tudo isso parece estar sendo questionado porque as escolas estão sendo obrigadas também, por força de lei, a oferecer uma disciplina imposta pelas Diretrizes Nacionais Curriculares para a Educação das Relações Étnico-Raciais e para o Ensino da História e Cultura Afro-Brasileira e Africana exaradas pelo Ministério da Educação e seu Conselho Nacional de Educação.

As Diretrizes, nascidas para ensinar aos estudantes a história da África e da cultura brasileira acabam por encorajar uma educação ou reeducação que quer transformar os cidadãos pessoas orgulhosas de seu "pertencimento étnico racial".

A lei diz claramente que é preciso valorizar a "diversidade" a fim de superar as desigualdades étnico-raciais. E afirma:

Políticas de reparações e de reconhecimento formarão programas de ações afirmativas, isto é, conjuntos de ações políticas dirigidas à correção de desigualdades raciais e sociais, orientadas para oferta de tratamento diferenciado com vistas a corrigir desvantagens e marginalização criadas e mantidas por estrutura social excludente e discriminatória. Ações afirmativas atendem ao determinado pelo Programa Nacional de Direitos Humanos, bem como a compromissos internacionais assumidos pelo Brasil, com o

\footnotetext{
${ }^{22}$ Sobre nosso sistema de classificação racial ver Nogueira (1985) e Teixeira (1986)
} 


\title{
perifèria
}

Número 5, Diciembre 2006

www.periferia.name

\begin{abstract}
objetivo de combate ao racismo e a discriminações, tais como: a Convenção da UNESCO de 1960, direcionada ao combate ao racismo em todas as formas de ensino, bem como a Conferência Mundial de Combate ao Racismo, Discriminação Racial, Xenofobia e Discriminações Correlatas de 2001. (p.12)
\end{abstract}

As diretrizes afirmam ainda que os movimentos negros têm comprovado a dura experiência de "fingir ser o que não é para ser reconhecido... de quão dolorosa pode ser a experiência de deixar-se assimilar por uma visão de mundo, que pretende impor-se como superior e por isso universal e que obriga a negarem a da tradição do seu povo". (p.11)

Para finalizar, uma espécie de profecia ameaçadora:

Se não é fácil ser descendente de seres humanos escravizados e forçados à condição de objetos utilitários ou a semoventes, também é difícil descobrir-se descendente dos escravizadores, temer, embora veladamente, revanche dos que, por cinco séculos, têm sido desprezados e massacrados.

Para reeducar as relações étnico-raciais no Brasil é necessário fazer emergir as dores e medos que têm sido gerados. É preciso entender que o sucesso de uns tem o preço da marginalização e da desigualdade impostas a outros. E então decidir que sociedade queremos construir daqui para frente. $(p .11)^{23}$

O que se pode apreender da leitura dessa lei estabelecida pelo Conselho Nacional de Educação é que ela apresenta um Brasil radicalmente distinto dos textos e livros escolares anteriores que falam de mistura, de caldo de cultura etc. As Diretrizes

\footnotetext{
${ }^{23}$ Essas diretrizes foram criticadas por José Roberto Pinto de Góes que se espantou com as expressões utilizadas no documento: "De que revanche estão falando? E o que dizer dessa história de fazer emergir dores e medos"? (Góes, 2004). Peter Fry também já tinha visto nelas um caminho seguro para a construção de um país dividido racialmente Fry (2005).
} 


\section{perifèria}

Número 5, Diciembre 2006

www. periferia. name

citadas representam uma visão alinhada aos Movimentos Negros, citados várias vezes ao longo do texto, como dissemos em outro lugar Maggie (2006).

Assim, as cores, que antes individualizavam, parecem que agora serão abolidas para serem transformadas duas que se opõem. Os estudantes são ensinados a se pensar não mais como indivíduos de várias cores, mas como pertencendo a dois grandes grupos "étnicos" os brancos e os negros. Mas a lei conhecida como lei 10639 não para aí porque, como foi dito mais acima, ela frisa que os mestres devem ensinar os estudantes a se "orgulhar de sua pertença étnica".

Diante desses resultados que temos até aqui nos perguntamos: será lícito criar políticas que se afastem da estratégia até então adotada pelos estudantes cariocas? Será justo fazer recair sobre os ombros desses jovens não só a responsabilidade como as possíveis conseqüências dessa engenharia social baseada na "raça" e que entroniza marcadores "raciais" como critério de distribuição de direitos e estratégia de vida como quer o juiz do Paraná citado no início deste capítulo? Temos o direito de em nome do anti-racismo correr o risco de transformar os pátios dessas escolas em espaços divididos entre brancos e negros definidos por lei? Reparar erros do passado com uma lei que institui legalmente dois grupos raciais é a conseqüência lógica da política ora proposta para o nosso país.

Será que os resultados que acabamos de descrever e que se referem a escolas de ensino médio do Rio de Janeiro não seriam um alerta contra essas políticas propostas nos dois projetos de lei? Como vimos, esses estudantes e suas famílias escolheram um outro caminho e estratégia para enfrentar os desafios colocados pela discriminação e pelo racismo que vivem nas escolas. Criar políticas que farão recair sobre os ombros desses jovens não só a responsabilidade como as possíveis conseqüências de uma política baseada na "raça" para reparar "o erro histórico da escravidão" parece ser um caminho sem volta. Se nossos jovens hoje não se vêem divididos em grupos e se pensam como indivíduos, em várias esferas da vida social, será justo instituir, de cima para baixo, uma política ou uma "engenharia social" que os dividirá legalmente em duas metades, uma branca e outra negra, 


\section{perifèria}

Número 5, Diciembre 2006

www. periferia. name

obrigando-os, logicamente, a se pensarem pertencentes a dois grupos raciais ou "étnicos" distintos?

Estas perguntas não saíram da minha cabeça ao longo desses quase dois anos de convivência nessas escolas pesquisadas.

Em 1954 Hannah Arendt (2004) posicionou-se contra o processo em curso de dessegregar as escolas nos Estados Unidos da América. Naquela altura, as leis que segregavam brancos e negros no sul dos EUA não haviam ainda sido abolidas e a Suprema Corte decidiu iniciar a dessegregação das escolas. Alunos negros eram obrigados a freqüentar escolas antes segregadas e onde estudavam os brancos. A filósofa alemã exilada nos EUA posicionou-se contra esta decisão apesar de ser uma decisão considerada libertária para a maioria dos americanos. Segundo ela era impossível lutar contra o racismo sem abolir as leis que separavam os cidadãos em duas "raças". O anti-racismo, segundo a autora, teria que começar retirando do estado toda e qualquer regra baseada em "raça", pois estas leis violam o princípio mais fundamental da República. Se no caso dos EUA era preciso antes de mais nada abolir as leis racistas criadas após a abolição, no Brasil não podemos também inverter o processo e criar leis racializadas para depois aboli-las.

A solução ora apresentada como política pública, a reserva de vagas para negros nas universidades federais e o chamado Estatuto da Igualdade Racial parecem atacar pelo lado mais frágil. Eles propõem a construção legal de barreiras intransponíveis entre os futuros candidatos ao ensino superior e que estudam em escolas públicas e fazendo isso, reproduzem o que Hannah Arendt via nos EUA naqueles anos 1950:

A série de acontecimentos que se seguiu à decisão da Suprema Corte, depois dos quais o governo se comprometeu a travar a sua batalha pelos direitos civis na esfera da educação e escolas públicas, impressiona pelo senso de futilidade e amargura necessária, como se todas as partes envolvidas soubessem muito bem que nada estava sendo realizado sob o pretexto de que alguma coisa estava sendo feita. Arendt 2004 p. 265 


\section{perifèria}

Número 5, Diciembre 2006

www.periferia. name

\section{Referências Bibliográficas}

Arendt, Hannah. Reflexões sobre Little Rock em Responsabilidade e julgamento, São Paulo: Companhia das Letras, 2004.

Bevilaqua, Ciméia Barbato: A implantação do "Plano de metas de inclusão racial de social" na Universidade Federal do Paraná", relatório de 2005 apresentado no seminário da Rede Observa: Acompanhando as ações afirmativas no ensino superior. www.observa.ifcs.urfj.br acesso em 16 de julho de 2006.

Carrara, Sérgio, Ramos, Silvia. Política, Direitos, Violência e Homossexualidade: Pesquisa 9ạ Parada do Orgulho GLBT - Rio 2004. Rio de Janeiro: CEPESC, 2005.

Carvalho, José J orge de. Inclusão Étnica e Racial no Brasil. A questão das cotas no ensino superior. São Paulo: Attar ed. 2005

Cunha, Olívia Gomes da. Intenção e gesto: política de identificação e repressão à vadiagem no Rio de Janeiro Rio de Janeiro: Arquivo Nacional, 2005.

Fry, Peter Henry. A persistência da raça: ensaios antropológicos sobre o Brasil e a África Austral, Rio de Janeiro: Editora Civilização Brasileira, 2005.

Fry, Peter Henry e MAGGIE, Yvonne. O debate que não houve em A persistência da raça: ensaios antropológicos sobre o Brasil e a África Austral, Rio de Janeiro: Editora Civilização Brasileira, 2005.

Góes, José Roberto Pinto de. O racismo vira lei, O Globo, 16/08/2004.

. Tema em Debate: Cotas raciais, O Globo, 14/07/2006.

Machado, Elielma Aires. Desigualdades raciais e ensino superior: Um estudo sobre a introdução das leis de reservas de vagas para egressos de escolas públicas e cotas para negros, pardos e carentes da UERJ: 2004. Tese de doutorado apresentada ao Programa de Pós-Graduação em Sociologia e Antropologia da UFRJ, Rio de Janeiro.

Maggie, Yvonne. Cor, hierarquia e sistema de classificação: a diferença fora do lugar, Revista Estudos Históricos, n.14, Rio de Janeiro: 1994. 


\section{perifèria}

Número 5, Diciembre 2006

www. periferia. name

A reserva de vagas na universidade brasileira. Revista Estudos Avançados, n. 18, vol 50, 2004a.

. Cotas Raciais - construindo um país dividido, Revista do Programa de Pós Graduação em Economia, vol. 6, 2004b.

. Uma nova pedagogia racial? São Paulo: Dossiê Especial Revista da USP, n. 68 dezembro 2005 jan/fev 2006.

A escola vista por dentro: Relatório 2006 apresentado no seminário da Rede Observa: Acompanhando as ações afirmativas no ensino superior. www.observa.ifcs.urfj.br acesso em 16 de julho de 2006.

Maio, Marcos Chor e Santos, Ricardo Ventura. Política de cotas raciais, "os olhos da sociedade" e os usos da antropologia: o caso do vestibular da Universidade de Brasília (UnB), Horizontes Antropológicos, Ano 11, número 23, Janeiro/junho de 2005.

Moutinho, Laura. Razão, Cor e Desejo: Uma Análise Comparativa sobre Relacionamentos Afetivo-Sexuais inter-raciais no Brasil e na África do Sul.. São Paulo: UNESP, 2004. v. I. 450 p.

Monteiro, Fabiano Dias. Retratos em branco e preto, retratos sem nenhuma cor: a experiência do disque-racismo da Secretaria de segurança pública do Estado do Rio de Janeiro. Dissertação de Mestrado no Programa de Pós-Graduação em Sociologia e Antropologia da UFRJ, Rio de Janeiro, 2003.

Nogueira, Oracy. Preconceito racial de marca e preconceito racial de origem em Tanto preto quanto branco. São Paulo: editora T.A. Queiroz, 1985.

Ramos, Carla. Lei de cotas na universidade: O caso das universidades estaduais do Rio de Janeiro, Dissertação de mestrado apresentada em 2005 ao Programa de Pós-Graduação em Sociologia e Antropologia UFRJ, Rio de Janeiro.

Teixeira, Moema de Poli. Família e identidade racial, dissertação de mestrado no PPGSA/UFRJ, 1986.

Diretrizes Curriculares Nacionais para a Educação das Relações Étnico-Raciais e 


\section{perifèria}

Número 5, Diciembre 2006

www.periferia. name

para o Ensino de História e Cultura Afro-Brasileira e Africana, Brasília: Secad/MEC, 2005.

Livro ilustrado da Copa do Mundo Fifa 2006 São Paulo: editora Panini, 2006 